\title{
Corrosion Behavior of Silicon-Bearing Steel in a Wet/Dry Environment Containing Chloride Ions
}

\author{
Toshiyasu Nishimura \\ Metals Structural Research center, National Institute for Materials Science (NIMS), \\ Tsukuba 305-0047, Japan
}

The rust of Si-bearing steel was analyzed by EPMA, XRF, XPS and TEM, and the electrochemical behavior of the rusted steel was investigated by the electrochemical impedance spectroscopy (EIS) method after wet/dry cyclic corrosion test with chloride ions.

The 2.0 mass\% Si-bearing steel showed high corrosion resistance compared to carbon steel (SM) in the corrosion test. EPMA and XPS showed that $\mathrm{Si}$ existed as a intermediate oxidized state such as $\mathrm{Si}^{2+}$ in the inner rust layer for Si-bearing steel. TEM showed that nano-scale complex oxides containing $\mathrm{Si}$ were formed in the inner rust of the Si-bearing steel.

EIS measurement was taken to estimate the rust resistance (Rrust) and corrosion reaction one (Rt) of the rusted steel. It was found that Rrust and Rt of Si-bearing steel were much larger than those of SM after the rust formation. The corrosion of Si-bearing steel could be suppressed by the formation of the nano-scale complex oxide containing $\mathrm{Si}$ in inner rust layer to prevent the penetration of $\mathrm{Cl}$ ions. [doi:10.2320/matertrans.MRA2007039]

(Received February 16, 2007; Accepted March 19, 2007; Published May 25, 2007)

Keywords: rust, atmospheric corrosion, silicon, chloride, electroprobe $x$-ray microanalysis, $x$-ray fluorescence spectroscopy, x-ray photoelectron spectroscopy, transmission electron microscopy, electrochemical impedance spectroscopy

\section{Introduction}

Recently it is very important to use the weathering steel to reduce the maintenance cost of infrastructure facilities. In addition there are many steel structures in coastal areas, it is necessary to use high resistant steels against the corrosion caused by air-borne salt particles. ${ }^{1)}$ Thus Ni-bearing weathering steels ${ }^{2)}$ that can be used in coastal environments have been proposed. However, $\mathrm{Ni}$ is a rare metal and hard to use for the recycle of steels.

While there have been many analyses of rust on the steels in mild environments, ${ }^{3-10)}$ there are many problems that remain unclear regarding the basic mechanisms of the rust formation $^{11)}$ and the effect of alloy elements ${ }^{12-14)}$ in saline environments. Therefore, in order to obtain the corrosion guidance for weathering steels that can be used in coastal environment, the thermodynamic stability of various rusts (Fe-X system) was investigated using a binary-phase potential-pH diagram. ${ }^{15)}$ Finally, it was indicated that $\mathrm{Al}$ and $\mathrm{Si}$ had the possibility to form stable complex-oxides with Fe. Moreover, Si does not prevent the recycle-use of steels that will be necessary in the future to take into the consideration of LCA (Life Cycle Assessment). However, there have been few reports about the effect of $\mathrm{Si}^{16,17)}$ on the atmospheric corrosion of steels in saline environment. In this study, the process of the formation and the electrochemical behavior were investigated on the rust of Si-bearing steels formed in a cyclic wet/dry condition. Specially, the chemical state of Si in the rust for Si-bearing steel was examined by using EPMA, XRF, XPS and TEM. Moreover the electrochemical behavior of the rust was investigated by the electrochemical impedance spectroscopy (EIS) method after wet/dry cyclic corrosion test with chloride ions. Finally, relation between the formation and electrochemical behavior of the rust was discussed for Si-bearing steel.

\section{Experimental Procedures}

\subsection{Wet/dry cyclic corrosion test ${ }^{11)}$}

The corrosion test consisted of 2 steps. 1st step was wetting process by putting on the sample surfaces with $0.4 \mathrm{Litter} / \mathrm{m}^{2}$ of a 0.5 mass $\% \mathrm{NaCl}$ solution. And 2nd step was drying process by keeping the specimen in a chamber maintained at $25^{\circ} \mathrm{C}, 60 \% \mathrm{RH}$ for 12 hours. Immediately before dropping a solution, the specimen was washed in distilled water and dried to prevent progressive salt accumulation. The sample materials were Si-bearing steel and carbon steel (SM), which composition was $0.05 \mathrm{C}-2.0 \mathrm{Si}-0.7 \mathrm{Mn}-0.01 \mathrm{P}-0.003 \mathrm{~S}-0.03 \mathrm{Al}-$ $0.003 \mathrm{~N}-0.002 \mathrm{O}-\mathrm{Fe}$, and $0.05 \mathrm{C}-0.2 \mathrm{Si}-0.7 \mathrm{Mn}-0.01 \mathrm{P}-0.003 \mathrm{~S}-$ $0.03 \mathrm{Al}-0.003 \mathrm{~N}-0.002 \mathrm{O}-\mathrm{Fe}$, respectively.

\subsection{Physical analysis of the rust ${ }^{12-15)}$}

For the analysis of the rust, Electroprobe X-ray microanalysis (EPMA), X-ray Fluorescence Spectroscopy (XRF), $\mathrm{X}$-ray photoelectron spectroscopy (XPS) and Transmission electron microscopy (TEM) were used. The EPMA was carried out using a JEOL JXA-8600MX, with an acceleration voltage of $15 \mathrm{kV}$, an irradiation current of $1 \times 10^{-7} \mathrm{~A}$, and a beam diameter of $1 \mu \mathrm{m}$. After the steel was mounted in the resin, it was mirror polished using emery papers, diamond paste and $\mathrm{Al}_{2} \mathrm{O}_{3}$ powder. Then carbon was evaporated onto the specimen in order to compensate the charging effects. A cross section of the rusted steel was examined. The distribution of $\mathrm{Si}$ in the rust was measured to identify the existing location of Si. Moreover the chemical state of Si in the rust was measured by using $\mathrm{Si} \mathrm{K} \alpha$ and $\mathrm{K} \beta$ characteristic $\mathrm{X}$-Ray. This new method has an advantage to investigate the chemical state of element in local area under $1 \mu \mathrm{m}$ of the diameter by using electron beam source.

The XRF was conducted using Rigaku 3080 with a Rh $\mathrm{X}$-ray source and beam diameter $20 \mathrm{~mm}$. The chemical state of $\mathrm{Si}$ in the rust was measured by using $\mathrm{Si} \mathrm{K} \alpha$ and $\mathrm{K} \beta \mathrm{XRF}$ 
spectra. XRF samples were prepared by using standard chemicals for $\mathrm{Si}$ and $\mathrm{SiO}_{2}$ distributed in the resin.

For the XPS, a SSI SSX-100 was used, with an Al k $\alpha$ Xray source and beam diameter $600 \mu \mathrm{m}$. After the rust on the steels were scraped using a spatula of brass, the powder was mounted on a pure In plate. The sample for XPS was covered with a Ni mesh and electron with acceleration voltage of $1 \mathrm{~V}$ was irradiated in order to compensate the charging effects. Moreover, the chemical state of Si was investigated using its $\mathrm{Si} 2 \mathrm{~s}$ and $2 \mathrm{p}$ spectrum, where the binding energy was corrected by that of the adventitious carbon (C $1 \mathrm{~s}=$ $284.6 \mathrm{eV}$ ).

For the TEM observation with Philip CM30, the rust was cut by FIB (Focused Ion Beam) from the inner layer. EDXS (Energy dispersing X-ray) analysis was carried out using PV9900 (EDAX Co., Ltd) in order to identify the chemical composition of the rust and select the Si-rich oxides.

\subsection{EIS measurement of the rust ${ }^{11)}$}

After the corrosion test, the electrodes were fabricated, and EIS measurements were carried out. EIS measurements were taken in $0.1 \mathrm{M} \mathrm{Na} \mathrm{Na}_{4}$ solution, under the following conditions: two electrodes system, measurement frequency range of $20 \mathrm{kHz}$ to $0.3 \mathrm{mHz}$, and applied voltage of $10 \mathrm{mV}$. Because it takes 5 hours for EIS measurement to get all results up to $0.3 \mathrm{mHz}$, the rust is changing in the $\mathrm{NaCl}$ solution during measurements. By comparing the EIS values at $1.0 \mathrm{mHz}$ after $0,5,24$ hours, it was found that there were little changes in the EIS results of the rusted steel measured in $\mathrm{Na}_{2} \mathrm{SO}_{4}$ solution. Thus it need technically for using $\mathrm{Na}_{2} \mathrm{SO}_{4}$ solution to keep the rust condition in the EIS measurement.

\section{Results and Considerations}

\subsection{Analysis of the rust on Si-bearing steel}

The corrosion resistance of the Si-bearing steel was evaluated by 40 cycles of a wet/dry corrosion test. The amount of corrosion was measured by the weight loss of the steels after removing the rust. The rust was removed by the wire brush in the Ammonium hydrogen citrate solution $\left(\mathrm{HOC}(\mathrm{COOH})\left(\mathrm{CH}_{2} \mathrm{COONH}_{4}\right)_{2}\right)$ at $60^{\circ} \mathrm{C}$. The amount of corrosion at 30 cycles for the Si-bearing steel was about $85 \%$ of that of carbon steel (SM). It was clear that the addition of $\mathrm{Si}$ had an effect in environments containing chlorides. In order to clarify the corrosion-resistance mechanism of Sibearing steel, the structural state of the rust was investigated.

The surface layer of rust for a sample of Si-bearing steel was analyzed by EPMA. From the investigation of the distribution of $\mathrm{Si}$ in the rust layer, it was found that $\mathrm{Si}$ was concentrated in the inner part of the rust layer. Then the chemical state of $\mathrm{Si}$ in this concentrated layer was newly measured by using $\mathrm{Si} \mathrm{K} \alpha$ and $\mathrm{K} \beta$ characteristic X-rays of EPMA. Figure 1(A) shows the results of an analysis of a test sample subjected to 20 cycles of the corrosion test, and of the standard materials $\mathrm{SiO}_{2}$ and metallic silicon $(\mathrm{Si})$. The peak position of the $\mathrm{K} \alpha$ characteristic $\mathrm{X}$-ray for $\mathrm{Si}$-bearing steel is different from that of the standard materials $\mathrm{SiO}_{2}$ and metallic silicon, appearing middle position between the these two peaks. Furthermore, Figure 1(B) shows the same kind of results for an analysis using $\mathrm{Si} \mathrm{K} \beta$ characteristic X-rays. The
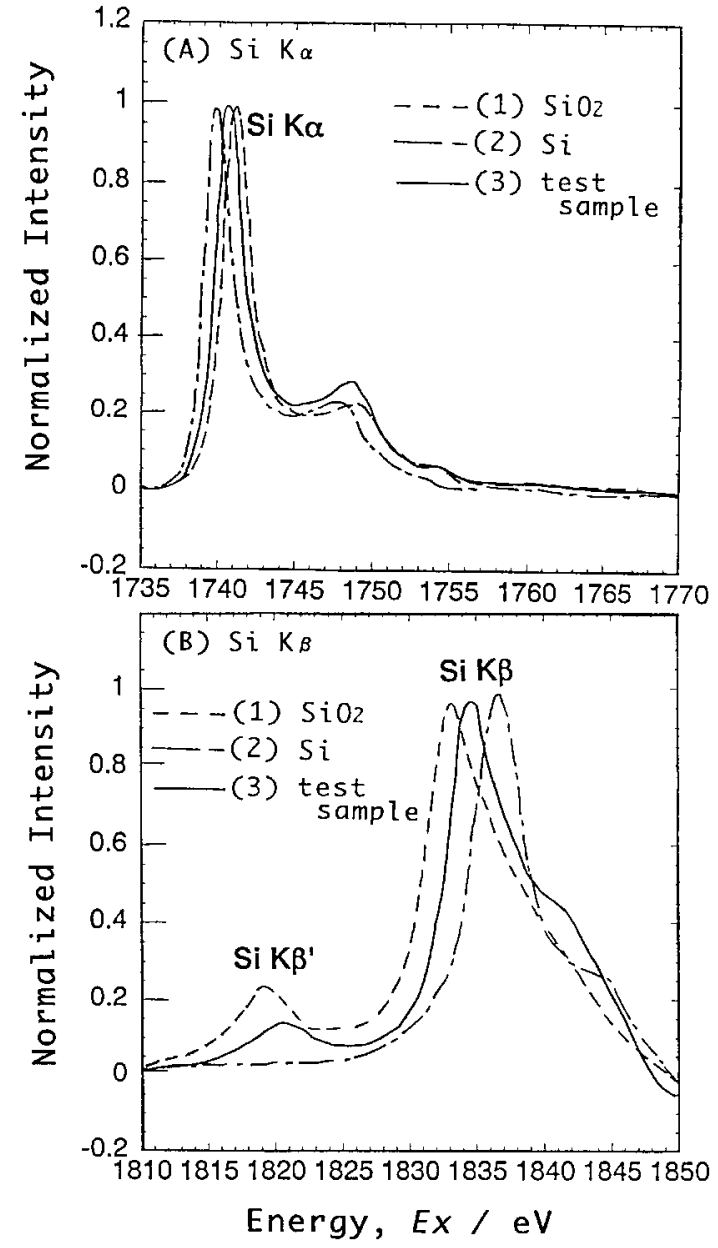

Fig. 1 Characteristic X-rays spectra of (A) $\mathrm{Si} \mathrm{K} \alpha$ and (B) Si $\mathrm{K} \beta$ from the rust of Si-bearing steel and standard reference chemicals $\left(\mathrm{SiO}_{2}, \mathrm{Si}\right)$ obtained by EPMA.

peak position of the $\mathrm{Si} \mathrm{K} \beta$ characteristic X-ray appears between those of two materials. What is more, in comparison to the peak strength values of $\mathrm{Si} \mathrm{K} \beta^{\prime}$ of these two standard materials, that of the Si-bearing steel is shown in the middle value between them. From these results, it is suggested that the $\mathrm{Si}$ in the rust layer is not in a metallic but an oxidized state, however it is in a different chemical bonding state to $\mathrm{SiO}_{2}$.

As a small amount of characteristic X-rays spectra were analyzed, it was a little difficult to determine chemical state of Si based only on the above analysis. Thus we carried out a further analysis using XRF on the rust gathered from a sample after 20 cycles of the corrosion test. Figure 2(A) shows the results of an analysis of rust for Si-bearing steel and the standard materials. The peak position of the $\mathrm{Si} \mathrm{K} \alpha$ for test sample is different from that of the metallic silicon and similar to that of $\mathrm{SiO}_{2}$. Figure 2(B) shows the spectrum of $\mathrm{Si} \mathrm{K} \beta$ for the rust. The peak of the $\mathrm{Si} \mathrm{K} \beta$ for test sample shows the position between those of $\mathrm{Si}$ and $\mathrm{SiO}_{2}$. From these results, it is suggested that the $\mathrm{Si}$ in the rust layer is not in a metallic but an oxidized state.

Figure 3 shows the results of an XPS analysis on the rust for Si-bearing steel. Figure 3(A) shows the Si 2s XPS spectra of standard materials and the test sample. The peak position of the $\mathrm{Si} 2 \mathrm{~s}$ of test sample is existing between those two 

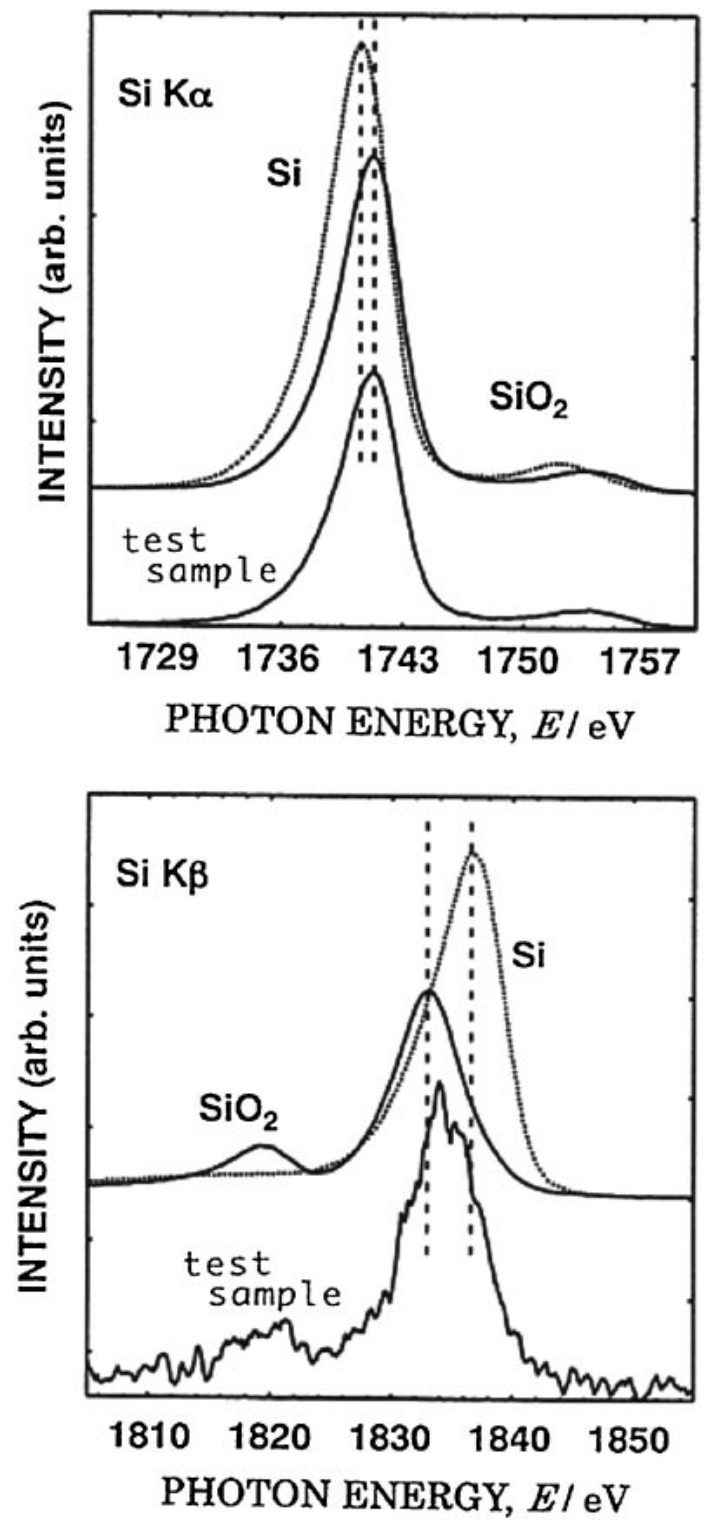

Fig. 2 XRF spectra of (A) Si K $\alpha$ and (B) $\mathrm{Si} \mathrm{K} \beta$ from the rust of Si-bearing steel and standard reference chemicals $\left(\mathrm{SiO}_{2}, \mathrm{Si}\right)$.

standard materials. Figure 3(B) shows similar results for a Si $2 p$ analysis. Here, because the Si $2 p$ spectrum is close to the Fe $3 \mathrm{~s}$ peak, the Fe $3 \mathrm{~s}$ spectrum taken from a standard test sample of $\mathrm{Fe}_{3} \mathrm{O}_{4}$ was used to separate the $\mathrm{Si} 2 \mathrm{p}$ spectrum of test sample. It is found that the position of the $\mathrm{Si} 2 \mathrm{p}$ peak for the $\mathrm{Si}$-bearing steel appears between that for the $\mathrm{SiO}_{2}$ and the metallic silicon. In summary, it was also observed from evaluation using XPS that the $\mathrm{Si}$ in the rust layer was in an oxidized, but in a different state of chemical bonding to that of $\mathrm{SiO}_{2}$.

Combining the results of the chemical analyses using EPMA, XRF and XPS, it can be stated that in the rust of Sibearing steel, the $\mathrm{Si}$ is existing in an oxidized, not metallic, state, but in a different form of chemical bonding to that of $\mathrm{SiO}_{2}$. The peak positions of each spectrum are summarized in the Table 1. Moreover the chemical shifts from the peak of metallic Si are estimated in the Table 1. The chemical shifts of Si-bearing steel from the peak of metallic Si are showing the almost half value than those of $\mathrm{SiO}_{2}$. Maekawa ${ }^{18)}$ stated
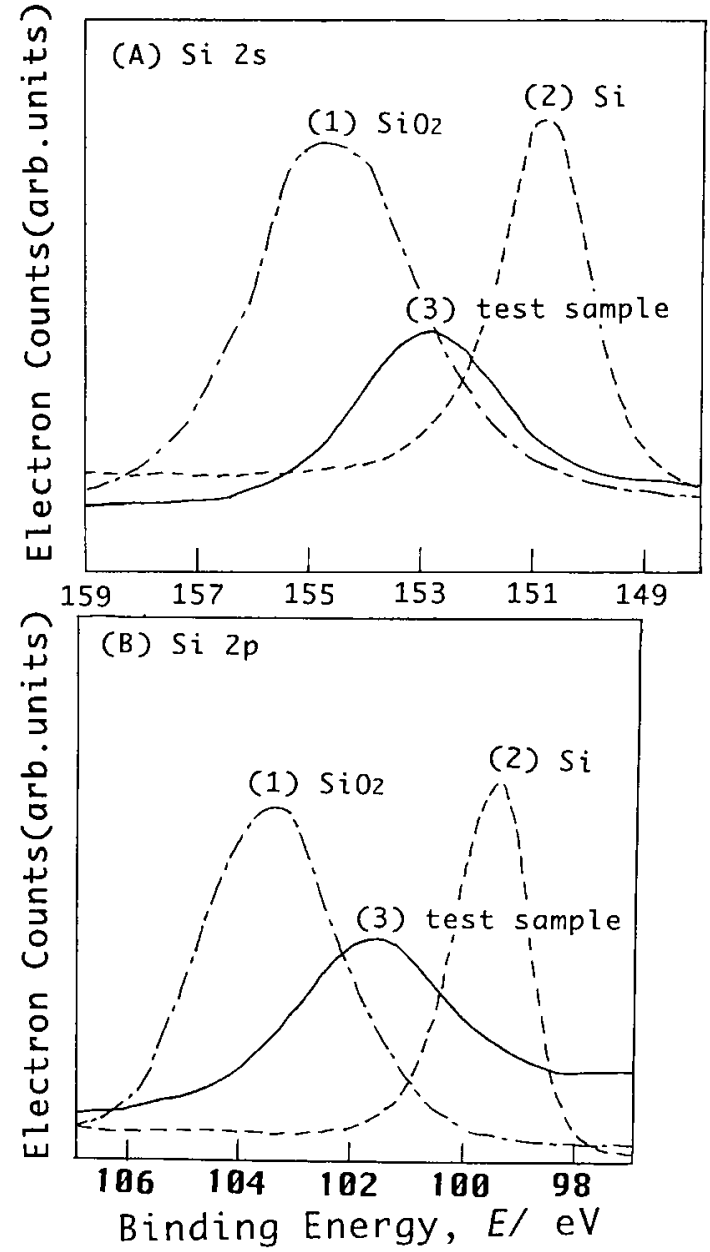

Fig. 3 XPS spectra of (A) Si 2s and (B) Si 2p from the rust of Si-bearing steel and standard reference chemicals $\left(\mathrm{SiO}_{2}, \mathrm{Si}\right)$.

that in analysis of Si based oxide compounds by XRF spectra, this peak appeared between that of $\mathrm{SiO}_{2}$ and metallic silicon, which was the same as our results. Since generation of XRF only differs by excitation source, and since it is created by the same process as the emission of characteristic X-rays, it is considered that the spectrum are showing the similar chemical shift between XRF and EPMA. Furthermore, Hollinger ${ }^{19)}$ stated that the chemical shifts of $\mathrm{Si}$ were depending on mainly the value of the valence of $\mathrm{Si}$, and that of $\mathrm{Si}^{2+}$ was showing half value than that of $\mathrm{SiO}_{2}$ from the peak of metallic silicon. In our results, the chemical shifts of $\mathrm{Si}$ bearing steel were showing almost half value than that of $\mathrm{SiO}_{2}$. Thus the chemical shift is thought to depend mainly on the valence of $\mathrm{Si}$, and $\mathrm{Si}$ is existing as a intermediate oxidized state such as $\mathrm{Si}^{2+}$ in the inner rust of Si-bearing steel.

In order to investigate the structure of the inner rust, TEM observation was conducted as shown in Fig. 4. The inner rust layer was cut by FIB (Fiber Ion Beam) as shown in Fig. 4(A). The rust containing $\mathrm{Si}$ is able to selected by EDXS analysis as in Fig. 4(B). From EDXS analysis, as the oxides contain both $\mathrm{Si}$ and $\mathrm{Fe}$, they make complex oxides of Fe-Si type. Moreover, the oxides which contain $\mathrm{Si}$ are observed as white particles in the bright field image as shown in Fig. 4(A). It is understood that the sizes of oxide particles which contain $\mathrm{Si}$ are nano-meter level, and there are enriched layers of white 
Table 1 Summary of the peak positions and chemical shifts for each spectra.

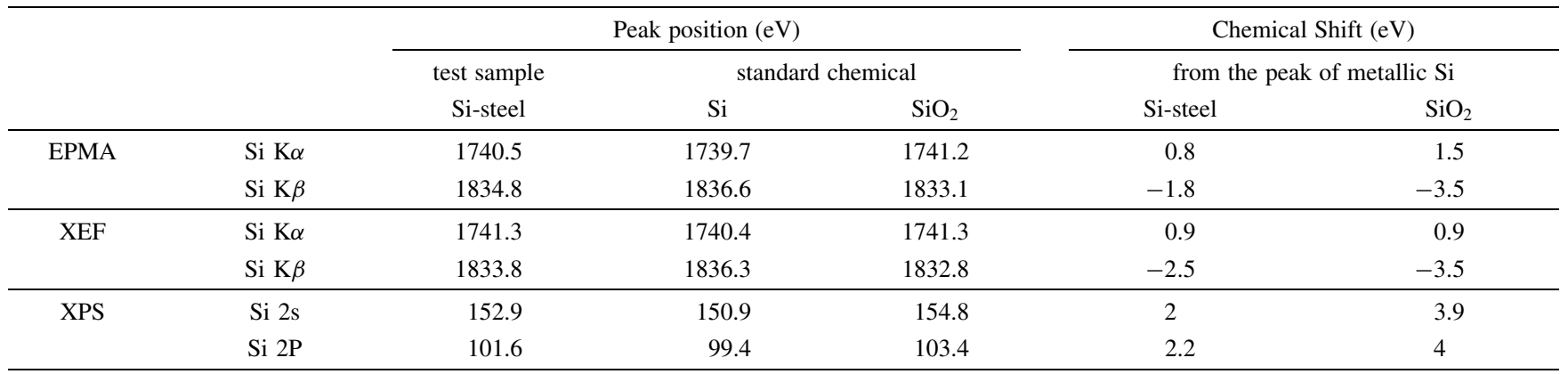

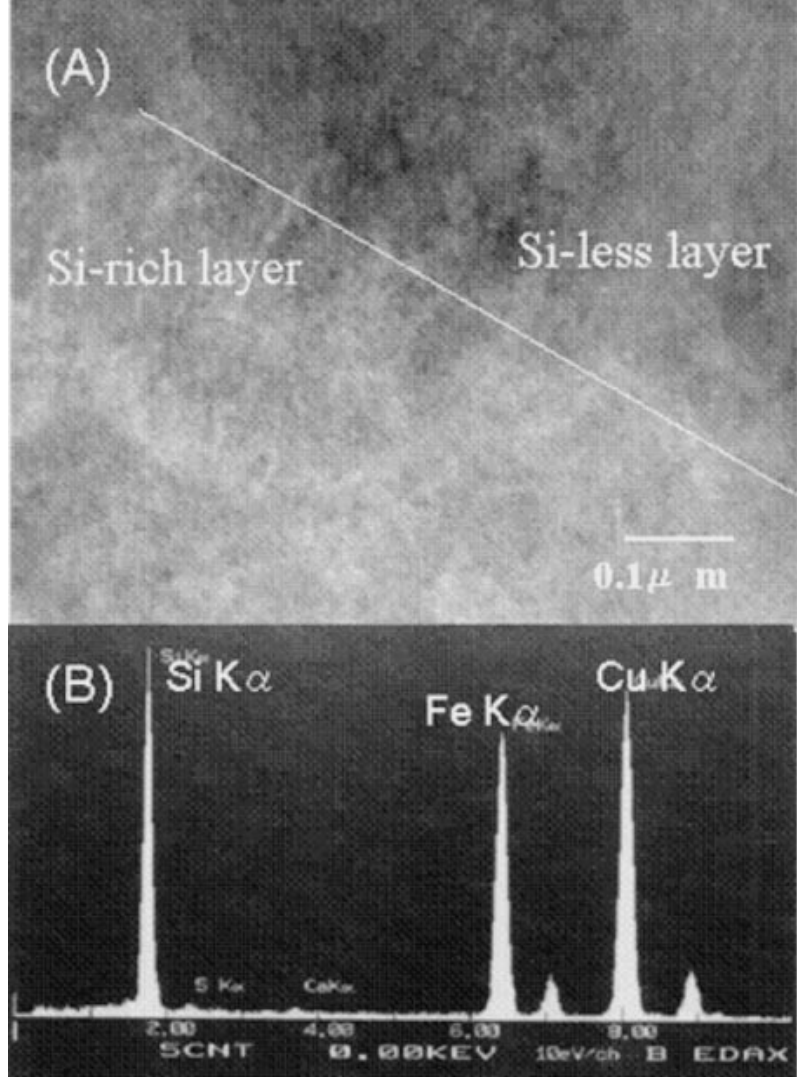

Fig. 4 FIB-TEM observation of the rust from the inner layer of Si-bearing steel. (A: bright field image, B: EDXS analysis)

particles. Thus these nano-scale complex oxides containing $\mathrm{Si}$ are enriched in the inner rust. From EPMA, XRF, and XPS analysis $\mathrm{Si}$ was identified as a intermediate oxidized state such as $\mathrm{Si}^{2+}$ and had a different chemical bonding to that of $\mathrm{SiO}_{2}$. Probably $\mathrm{Si}$ made complex oxides with $\mathrm{Fe}$ as $\mathrm{Si}^{2+}$ state in the inner rust, and chemical bonding was different from that of $\mathrm{SiO}_{2}$. Moreover, these nano-scale complex oxides $\left(\mathrm{Fe}_{-} \mathrm{Si}^{2+}-\mathrm{O}\right)$ could increase the corrosion resistance of the $\mathrm{Si}$ bearing steel. In this way, it can be understood that nanoscale complex oxides are possibly made in the rust of Sibearing steel, and they can increase the corrosion resistance of the steels.

\subsection{Evaluation of the electrochemical behavior of the rust by the EIS method}

Figure 5 shows the results of EIS measurements on the

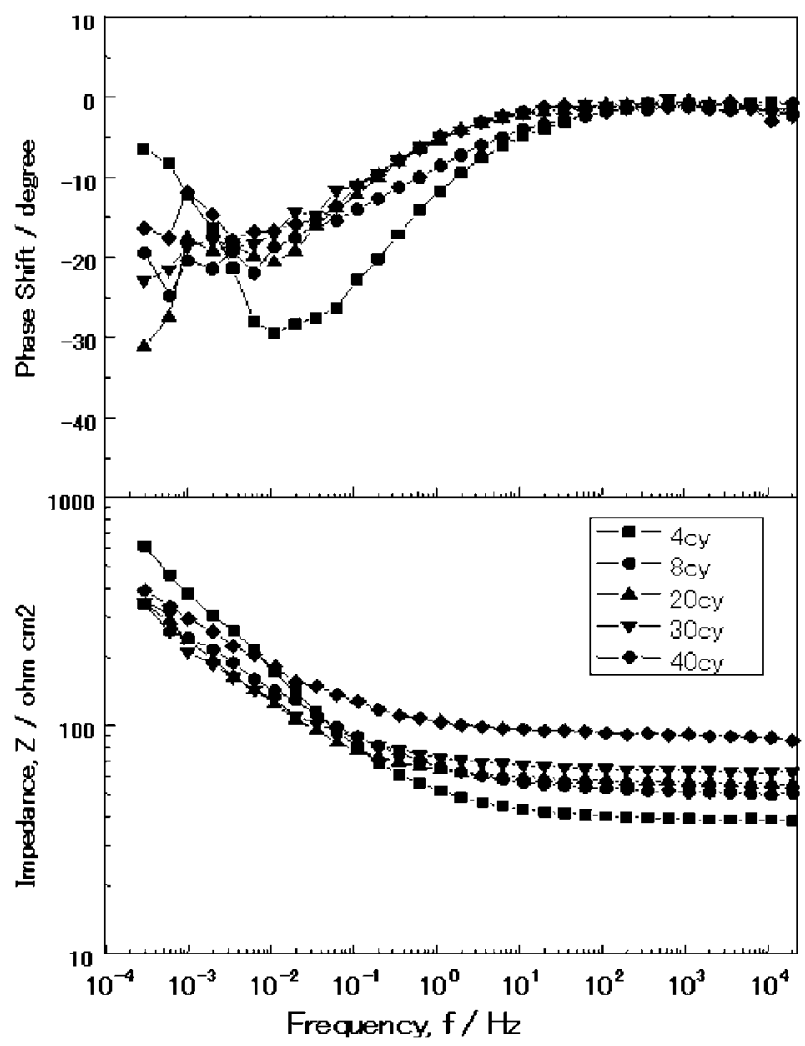

Fig. 5 Impedance and phase shift spectra of Si-bearing steel as a function of cycle of corrosion tests.

sample after the corrosion test. The resistance component at high frequencies more $1 \mathrm{~Hz}(\mathrm{Rh})$, the capacitance in the $1 \mathrm{mHz}$ to $1 \mathrm{~Hz}$ region $(\mathrm{C})$, and further the resistance component at frequencies less $1 \mathrm{mHz}(\mathrm{Rl})$ can be recognized. ${ }^{11)}$ As the amount of the rust increases with the number of test cycles, $\mathrm{Rh}$ also increases. Thus $\mathrm{Rh}$ can be related to the resistance of the rust (Rrust). Since the resistance of oxides is extremely high, it is considered that Rrust actually shows the resistance of the solution in the fine pores of the rust. On the other hand, the phase shift goes to 0 degree again at less than $1 \mathrm{mHz}$, showing the resistance component (Rl), which is considered to be the corrosion reaction resistance (Rt). When the amount of rust is small at 4 cycle, Rt can be verified at low frequency. Although when the amount of rust becomes large, Rt becomes difficult to recognize, it can be considered that impedance $(\mathrm{Z})$ at very low frequencies reflects Rt. In the following, considering the actual time for the measurement, we have used $\mathrm{Z}$ at the $0.3 \mathrm{mHz}$ to calculate Rt. 


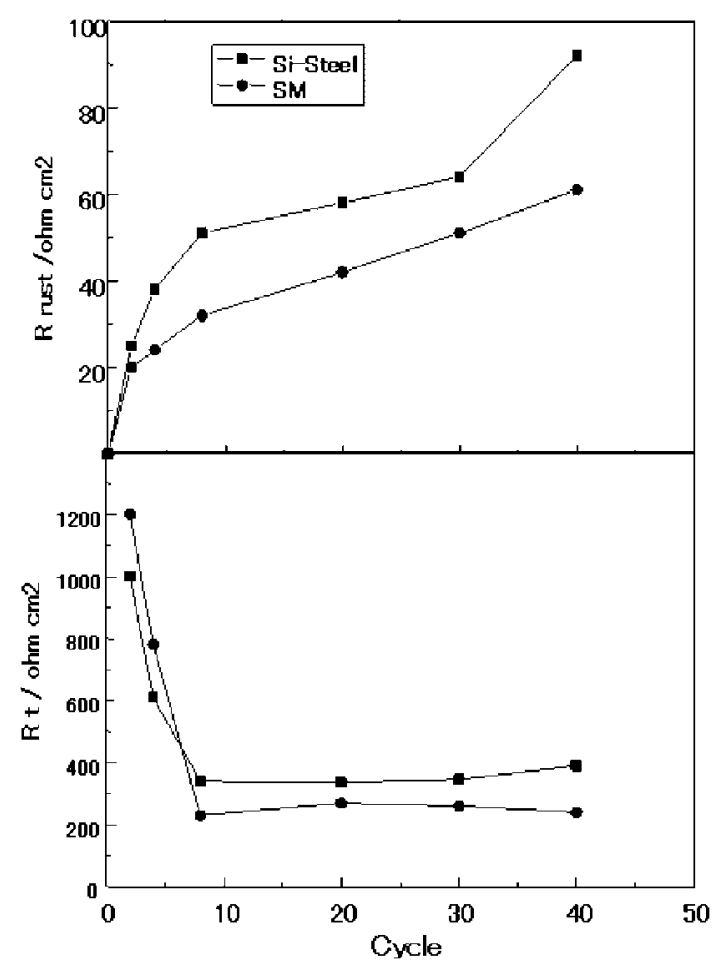

Fig. 6 Plots of impedance parameter (Rrust and Rt) of carbon steel (SM) and $\mathrm{Si}$-bearing one (Si-steel) as a function of corrosion test cycle.

Figure 6 shows the results of EIS measurements on Sibearing steel and SM conducted after the corrosion test, showing Rrust and Rt against the number of cycles. The Sibearing steel shows a higher value of Rrust than SM in each number of cycles. Since Rrust is the resistance of solution in the pores of the rust, this fact shows that the rust of Si-bearing has a finer structure than that of SM.

Both the Si-bearing and SM show high values of Rt at the initial cycles, however, they have smaller Rt after 8 cycles. This fact is considered to correspond to the increase of the cathodic reduction of rust as the rust is created. ${ }^{11)} \mathrm{Rt}$ shows a constant value after 8 cycles because the anodic reaction is suppressed as the surfaces is covered by the rust. Furthermore, the Si-bearing steel has a larger value of Rt than SM after 8 cycles. The main reason for this fact is considered that nano-scale complex oxide containing $\mathrm{Si}$ is formed in inner rust, which suppresses the anodic reaction. This phenomenon can be verified from the measurement of Rrust. As the formation of the rust proceeds, the value of Rrust and Rt of Si-bearing steel show larger than those of SM, which depends on the fineness of the rust. Figure 7 shows the schematic diagram of the corrosion mechanism of the rust of Si-bearing steel. In general, the rust has many micro-defects (pores) through which the chloride $(\mathrm{Cl})$ ions can penetrate to the base metal. However, the Si-bearing steel makes nano-scale complex oxides containing $\mathrm{Si}$ in inner rust at micro-defects, then increases the Rrust and Rt by the physical protection of the fine rust. Finally the Si-bearing steel could suppress the corrosion in saline environment.

The above corrosion test was conducted to form a thin film of rust using foils $\left(2 \times 10^{-5} \mathrm{~m}\right)$ of low alloy steel, and measured the rust membrane potential. ${ }^{18,19)}$ The results showed the rust film of SM had anion selective permeability,

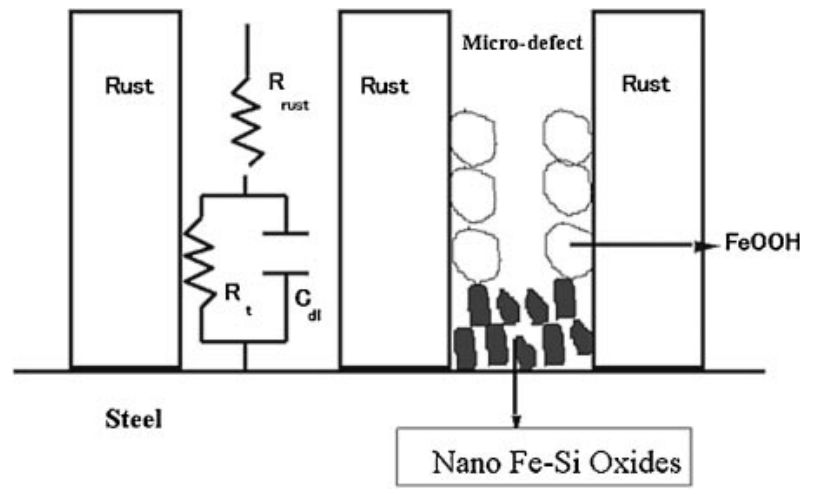

Fig. 7 Schematic diagram for the corrosion mechanism of the rust of Sibearing steel in wet/dry condition containing chloride ions.

however, that of Si-bearing steel had cation one. Thus the complex oxides containing $\mathrm{Si}$ made in the inner rust show possibly cation selective permeability and have the effect of preventing the passage of $\mathrm{Cl}$ ions through the rust. From this fact, it was understand that there was the effect of chemical prevention from the pass of $\mathrm{Cl}$ ions by making complex oxides containing $\mathrm{Si}$.

In this way, there are two reasons why Si-bearing steel increases Rt and suppresses corrosion; 1) the effect of physical protection by the creation of nano-scale oxides at the micro-defects, and 2) the effect of chemical prevention from the pass of $\mathrm{Cl}$ ions by the change in selective permeability by making complex oxides containing $\mathrm{Si}$.

\section{Conclusions}

A wet/dry cyclic corrosion test with $\mathrm{Cl}$ ions was performed on Si-bearing steel and the chemical state of $\mathrm{Si}$ in the rust and electrochemical behavior were analyzed.

(1) In a wet/dry cyclic experiment, Si-bearing steel showed smaller corrosion content compared to carbon steel (SM), and had excellent corrosion resistance.

(2) EPMA, XRF and XPS showed that $\mathrm{Si}$ in the rust of Sibearing steel was mostly existing as a intermediate state such as $\mathrm{Si}^{2+}$ in the complex oxide in inner rust layer. TEM showed that nano-scale complex oxides containing Si were enriched in the inner rust of the Si-bearing steel.

(3) An EIS measurement was taken of the corrosion test samples to find the rust resistance (Rrust) and corrosion reaction one (Rt), and the Rrust and Rt of Si-bearing steel were much larger than those of SM after the rust formation. In the Si-bearing steel, nano-scale complex oxides containing $\mathrm{Si}$ were formed in the inner rust, which could increase Rt and suppressed the corrosion.

\section{REFERENCES}

1) T. Kodama: Zairyo-to-Kankyo 49 (2000) 3-9.

2) M. Yamamoto and T. Kodama: Bull. ISIJ 4 (1999) 155-162.

3) U. R. Evans: Corrosion Science 9 (1969) 813-821.

4) T. Misawa, K. Asami, K. Hashimoto and Shimodaira: Corrosion Science 14 (1974) 279-289.

5) I. Suzuki, Y. Hisamatsu and N. Masuko: J. Electrochem. Soc. 127 (1980) 2210-2215. 
6) M. Stratmann, K. Bohnenkamp and T. Ramchandran: Corrosion Science 27 (1987) 905-926.

7) J. Dunnwald and A. Otto: Corrosion Science 29 (1989) 1167-1176.

8) H. E. Townsend: Corrosion 57 (2001) 497-501.

9) M. Yamashita, H. Miyuki, Y. Mastuda, H. Nagano and T. Misawa: Corrosion Science 36 (1994) 283-299.

10) H. Konishi, M. Yamashita, H. Uchida and J. Mizuki: Mater. Trans. 46 (2005) 329-336.

11) T. Nishimura, H. Katayama, K. Noda and T. Kodama: Corrosion 56 (2000) 935-941.

12) T. Nishimura, H. Katayama, K. Noda and T. Kodama: Corros. Sci. 42 (2000) 1611-1621.
13) T. Nishimura, K. Noda and T. Kodama: Corrosion 57 (2001) 753-758.

14) T. Nishimura, A. Tahara and T. Kodama: Mater. Trans. 42 (2001) 478483.

15) T. Nishimura and T. Kodama: Corros. Sci. 45 (2003) 1073-1084.

16) K. Y. Kim, Y. H. Hwang and J. Y. Yoo: Corrosion 58 (2002) 570-583.

17) K. Asami and M. Kikuchi: J. Japan Inst. Metals 66 (2002) 649-656.

18) T. Maekawa: J. Japan Inst. Metals 24 (1985) 186-192.

19) G. Hollinger and F. J. Himpsel: Appl. Phys. Lett. 44 (1984) 93-95.

20) K. Noda, T. Nishimura, H. Masuda and T. Kodama: J. Japan Inst. Metals 64 (2000) 767-770.

21) K. Noda, T. Nishimura, H. Masuda and T. Kodama: 196th Meeting of the Electrochemical Society ECS (1999) paper-524. 